\title{
STUDIES ON DIGITALIS. I. DIRECT EFFECTS ON PERIPHERAL VASCULAR RESISTANCE
}

\author{
By JOHN ROSS, JR., JOHN A. WALDHAUSEN AND EUGENE BRAUNWALD \\ WITH THE TECHNICAL ASSISTANCE OF ROBERT LEWIS
}

(From the Clinic of Surgery, National Heart Institute, Bethesda, Md.)

(Submitted for publication January 15, 1960; accepted February 5, 1960)

There is a substantial body of evidence which supports the view that the action of digitalis preparations is not limited to the heart. It had been suggested that the primary action of digitalis is extracardiac (1-3) and that the direct effects on the vascular bed may be responsible, in part, for its therapeutic action (4). However, in most studies, attention has been directed to the powerful positive inotropic action of this drug (5-10). The direct effects of digitalis on the peripheral circulation alone have not been clearly defined because of alterations in the cardiac output which usually accompany digitalization. The present study was designed to characterize the direct effects of several digitalis glycosides on vascular resistance in the dog. Two types of preparations were employed in which the circulatory effects resulting from the inotropic action of these drugs could be completely eliminated.

\section{METHODS}

Fifty-three mongrel dogs, ranging from 10.5 to 24.0 $\mathrm{kg}$ in weight, and averaging 15.4, were studied. Fiftyone dogs were premedicated with $2 \mathrm{mg}$ per $\mathrm{kg}$ morphine and received chloralose and urethan intravenously (11); in two dogs, pentobarbital (30 $\mathrm{mg}$ per $\mathrm{kg}$ ) was used instead of morphine. Two basic preparations were employed.

Preparation 1 . In 46 dogs, right thoracotomy was per-

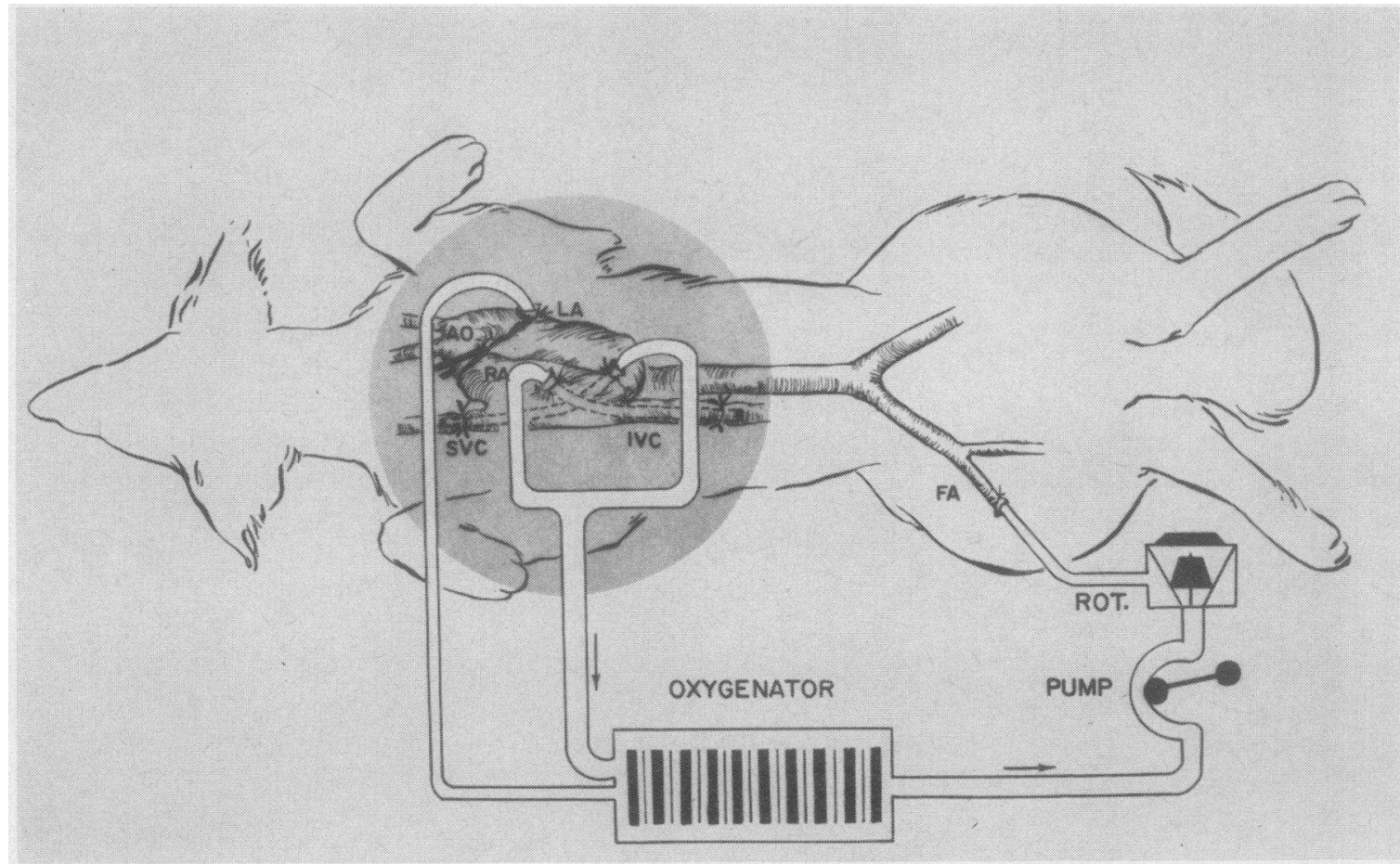

Fig. 1. Schematic drawing of Preparation 1. The superior vena cava (SVC) and inferior vena cava (IVC) are cannulated through the right atrium (RA). The aorta (AO) is occluded at its root. The left atrium (LA) is drained. Total body perfusion rate, through a cannula placed in the femoral artery (FA), is measured by the rotameter (ROT.). 


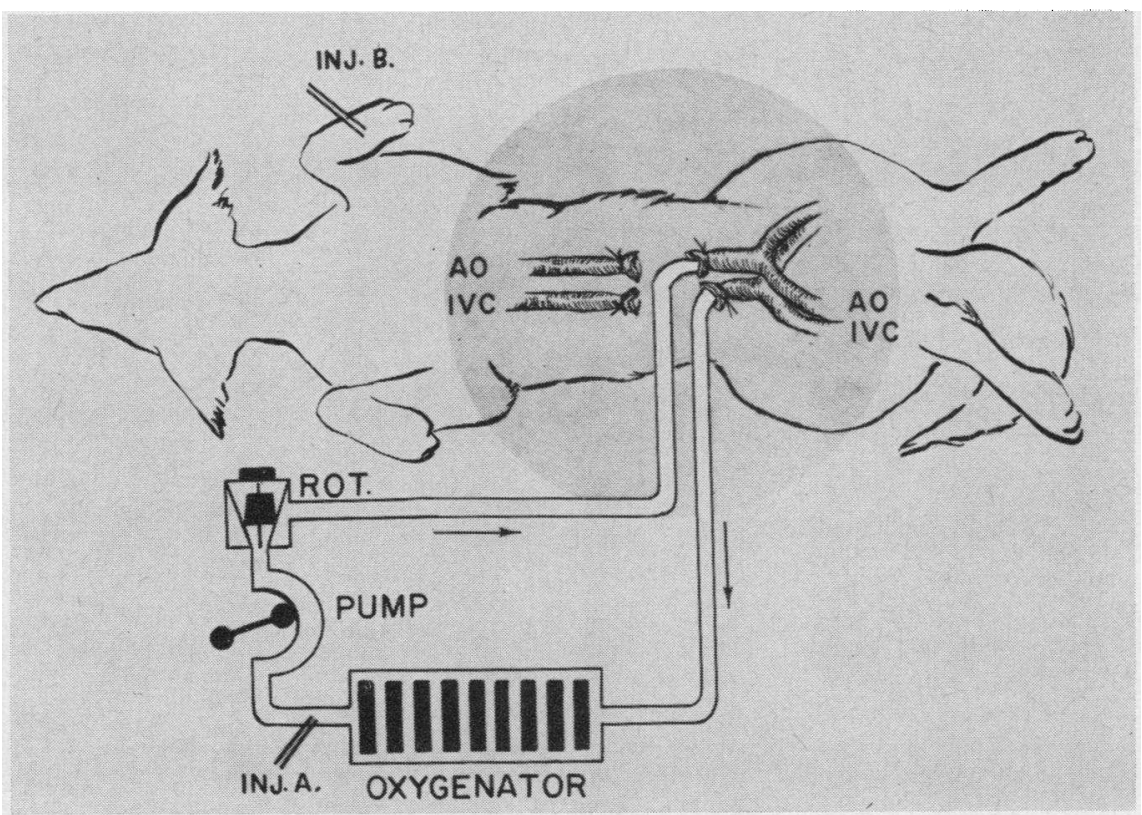

Fig. 2. Schematic drawing of Preparation 2. The aorta (AO) and inferior vena cava (IVC) are ligated in the lower abdomen and their distal ends cannulated. Injections of digitalis were carried out either into the lower segment (INJ. A.) or into the upper segment (INJ. B.).

formed and large cannulae were inserted into the inferior and superior venae cavae. A femoral artery was cannulated, and complete cardiopulmonary bypass was established, using a roller pump and rotating disc oxygenator (12). The volume of this extracorporeal circuit was approximately $1,350 \mathrm{ml}$. The ascending aorta was occluded above the coronary arteries in 44 of these dogs, thereby excluding the heart from the circulation. Total systemic blood flow was maintained at a constant rate throughout each experiment and was measured continuously with a recording rotameter (13) placed in the arterial pump line (Figure 1). Perfusion rates averaged $95 \mathrm{ml}$ per $\mathrm{kg}$ of body weight per minute (range 83 to 127). Cannulae for pressure measurements were passed into the lower aorta and inferior vena cava through branches of the femoral artery and vein, respectively. Pressures were measured with Statham pressure transducers and recorded continuously, together with systemic flow, on a multichannel direct-writing oscillograph. Blood temperature was maintained between $34^{\circ}$ and $37^{\circ} \mathrm{C}$ by means of a heating coil around the oxygenator. A gas mixture containing 1.5 per cent $\mathrm{CO}_{2}$ and $98.5 \mathrm{O}_{2}$ was employed for oxygenation. This basic preparation was employed as described above in 30 experiments. In the other 16 experiments it was modified as follows: a) In 4 dogs the celiac and superior mesenteric arteries were ligated through an upper abdominal incision. b) In 3 dogs complete bilateral adrenalectomy was performed through an upper abdominal incision. c) In 4 dogs ganglionic blockade was produced with 4 $\mathrm{mg}$ per $\mathrm{kg}$ of hexamethonium and maintained with a constant infusion of $0.2 \mathrm{mg}$ per $\mathrm{kg}$ per minute of this drug (14); this resulted in a decline in mean arterial pressure ranging from 13 to 45 per cent and averaging 22 per cent of the control pressure. d) In 5 dogs the femoral artery was incised longitudinally, taking care to avoid injury to the surrounding nerves; it was then cannulated and femoral arterial flow was continuously measured with a second recording rotameter.

Preparation 2. In 7 dogs a midline abdominal incision was made, the lower abdominal aorta and inferior vena cava were isolated, cross-clamped, and divided below the renal vessels. Large cannulae were then inserted into the distal ends of the aorta and inferior vena cava. The venous line was connected with the rotating disc oxygenator and oxygenated blood was delivered to the distal aorta by means of the roller pump. Flow was maintained at a constant rate which averaged $38 \mathrm{ml}$ per $\mathrm{kg}$ total dog weight per minute and was metered with the recording rotameter. Thus, the dog's own heart and lungs supported the upper portion of the circulation, while the extracorporeal circuit permitted almost complete humoral and hemodynamic isolation of the lower segment (Figure 2).

Control observations were made for at least $15 \mathrm{~min}$ utes in both preparations, prior to the injection of digitalis. The digitalis was administered as single rapid injections into the arterial side of the oxygenator in all dogs in Preparation 1, and in 4 dogs in Preparation 2. In 3 of the 7 dogs in Preparation 2, digitalis was injected intravenously into the upper segment. The duration of the pressor effect was calculated as the time interval be- 
TABLE I

Observations on the pressor effect of three digitalis preparations

\begin{tabular}{|c|c|c|c|c|c|}
\hline \multirow[b]{2}{*}{ Drug } & \multirow[b]{2}{*}{ Dose } & \multirow[b]{2}{*}{ Dogs } & \multirow[b]{2}{*}{ Other procedures } & \multicolumn{2}{|c|}{$\begin{array}{l}\text { Max. elevation of mean arterial } \\
\text { pressure above control }\end{array}$} \\
\hline & & & & Range & Mean \\
\hline \multirow{8}{*}{ Acetylstrophanthidin } & cat $U / \mathrm{kg}$ & no. & & $\%$ & $\%$ \\
\hline & 0.75 & $13^{*}$ & None & $32-137$ & 73 \\
\hline & 0.50 & 4 & None & $37-100$ & 68 \\
\hline & 0.25 & 5 & None & $29-38$ & 32 \\
\hline & 0.75 & 2 & Splanchnic arteries & $50-70$ & 60 \\
\hline & 0.60 & 2 & $\begin{array}{c}\text { ligated } \\
\text { Splanchnic arteries }\end{array}$ & $48-74$ & 61 \\
\hline & 0.50 & 3 & $\begin{array}{l}\text { ligated } \\
\text { Bilateral }\end{array}$ & & 40 \\
\hline & & & adrenalectomy & & \\
\hline \multirow{3}{*}{ Ouabain } & 0.50 & 6 & None & $43-134$ & 65 \\
\hline & 0.83 & 4 & Hexamethonium & $24-88$ & 56 \\
\hline & 0.83 & 5 & Femoral arterial & $58-106$ & 82 \\
\hline Lanatoside $\mathrm{C}$ & 0.50 & $3^{*}$ & None & $19-50$ & 34 \\
\hline
\end{tabular}

* One dog in each of these groups received Nembutal-chloralose-urethan anesthesia.

tween digitalis injection and the return of arterial pressure to the control level. A wide range of dosages was employed (Table I), and the relatively large increase in the circulating blood volume imposed by the extracorporeal circuit was considered when the higher doses were administered.

\section{RESULTS}

Preparation 1. The type of digitalis preparation employed, its dosage, the experimental design and the results obtained in 46 dogs are summarized in Table I. A tracing obtained in a representative experiment is reproduced in Figure 3. A substantial increase in arterial pressure was observed in all dogs following injection of each digitalis preparation. At a constant perfusion rate the percentage elevation of arterial pressure reflected an identical percentage increase in the peripheral vascular resistance. The total duration of this effect was shortest with acetylstrophanthidin, ranging from 9 to 30 minutes and averaging 19. The duration of effect was intermediate with ouabain, and longest with lanatoside $\mathrm{C}$. In eight dogs the experiment was terminated from 30 to 67 minutes after ouabain administration, before arterial pressure had returned to the control level. Similarly, the pressor effect of lanatoside $C$ persisted until the termination of the experiment at 50 minutes (two dogs) and 120 minutes (one dog) after injection.
Ligation of the splanchnic arteries did not appreciably modify the magnitude or duration of the pressor effect of acetylstrophanthidin (Table I). Bilateral adrenalectomy did not prevent the elevation of arterial pressure. The average of the maximum elevations of peripheral resistance produced by acetylstrophanthidin was less in the adrenalectomized dogs than in the dogs with intact adrenal glands, but there was a wide scatter and some overlap in response in both groups. Ganglionic blockade with hexamethonium did not prevent the pressor effects induced by ouabain; the average of the maximum elevations of peripheral resistance was lower than that in the dogs without ganglionic. blockade, but again, the scatter in responses in the two groups overlapped widely. A tracing obtained in a representative experiment of this type is reproduced in Figure 4.

It was noted that in all five dogs in which femoral arterial flow was metered it increased for a brief period concomitant with the initial rise in systemic arterial pressure (Figure 3 ). In four of these dogs a decline in flow to below control level ensued; this occurred at the peak of the ouabain-induced pressor effect, and was evidence of an elevation of hind limb vascular resistance. In the fifth dog, femoral arterial flow remained elevated and calculated hind limb vascular resistance was diminished. These observations sug- 
gest that the initial failure of the limb vessels to constrict synchronously with the total systemic vascular bed was due to the delayed arrival of digitalis in the hind limb as a result of the time

TABLE II

Observations on the effects of acetylstrophanthidin injection on the upper and lower segments of the circulation

\begin{tabular}{ccccc}
\hline \hline \multirow{2}{*}{$\begin{array}{c}\text { Experiment } \\
\text { Injection } \\
\text { site } \\
\text { (segment) }\end{array}$} & Dose & F. A. & B. A. \\
\cline { 4 - 5 } no. & & cat $U / k g$ & $\%$ & $\%$ \\
1 & lower & 0.25 & +38 & +3 \\
2 & lower & 0.125 & +28 & -4 \\
3 & lower & 0.125 & +31 & 0 \\
4 & lower & 0.125 & +42 & 0 \\
5 & upper & 0.25 & -14 & +17 \\
6 & upper & 0.25 & -17 & +102 \\
7 & upper & 0.25 & -6 & +14
\end{tabular}

${ }^{*}$ F.A. = femoral artery; B.A. = brachial artery. lag imposed by the femoral flowmeter circuit. In order to characterize this peripheral effect more precisely, Preparation 2 was employed.

Preparation 2. The results obtained in the seven experiments are summarized in Table II. When acetylstrophanthidin was injected into the lower circulatory segment, an increase in the lower (femoral) arterial pressure occurred in each instance, with little or no change in the upper (brachial) arterial pressure. Since the perfusion of the lower segment was maintained at a constant rate, the femoral arterial pressure change reflected a proportional increase in vascular resistance. In contrast, following the injection of acetylstrophanthidin into the upper circulatory segment, the pressor response was confined to this segment and a decline in pressure, presumably reflex in origin, occurred in the femoral artery.

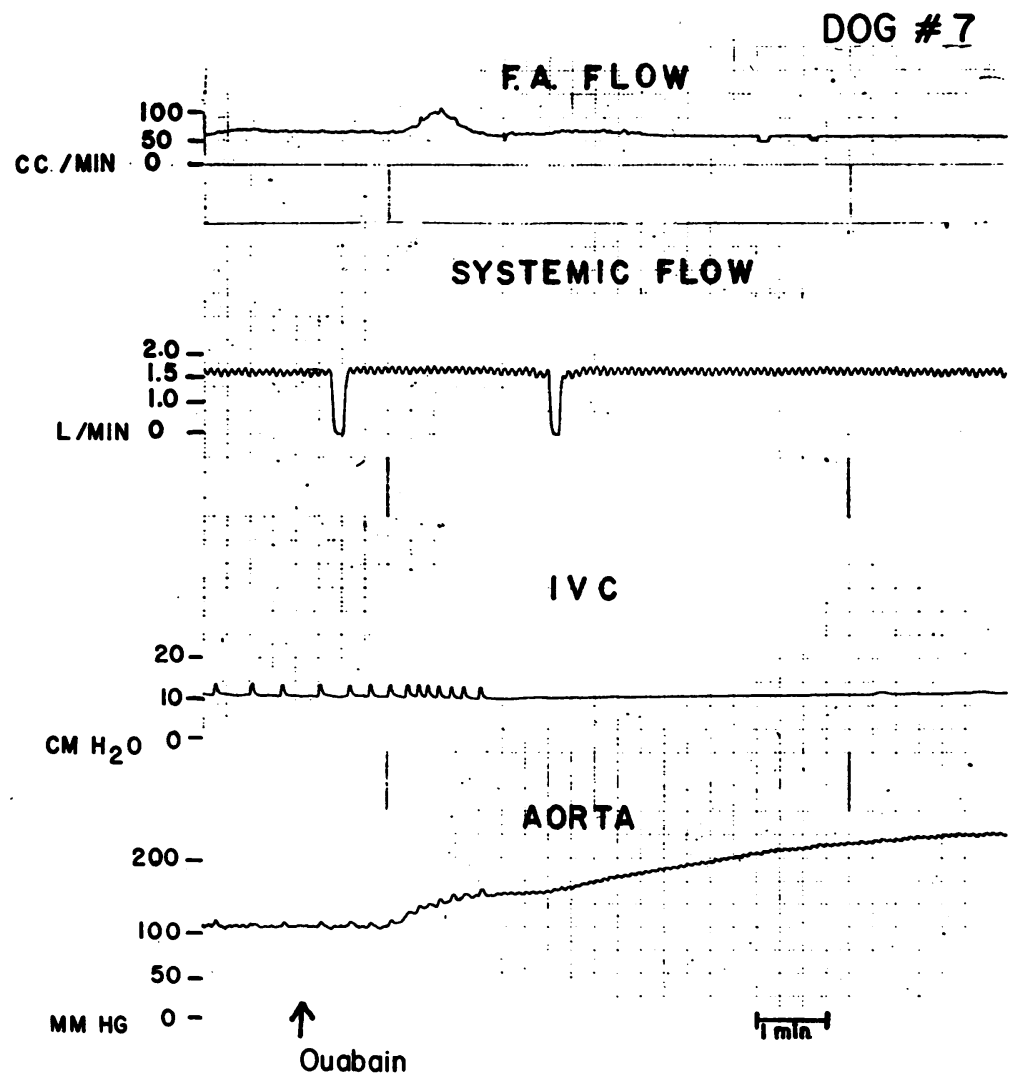

Fig. 3. Simultaneous Recordings of femoral ARterial flow (FA), SYSTEMIC FLOW, INFERIOR VENA CAVAL (IVC), AND AORTIC PRESSURES FOLLOWING INJECTION OF 0.83 CAT U PER KG OUABaIN. Two flowmeter baselines interrupt the systemic flow record. 


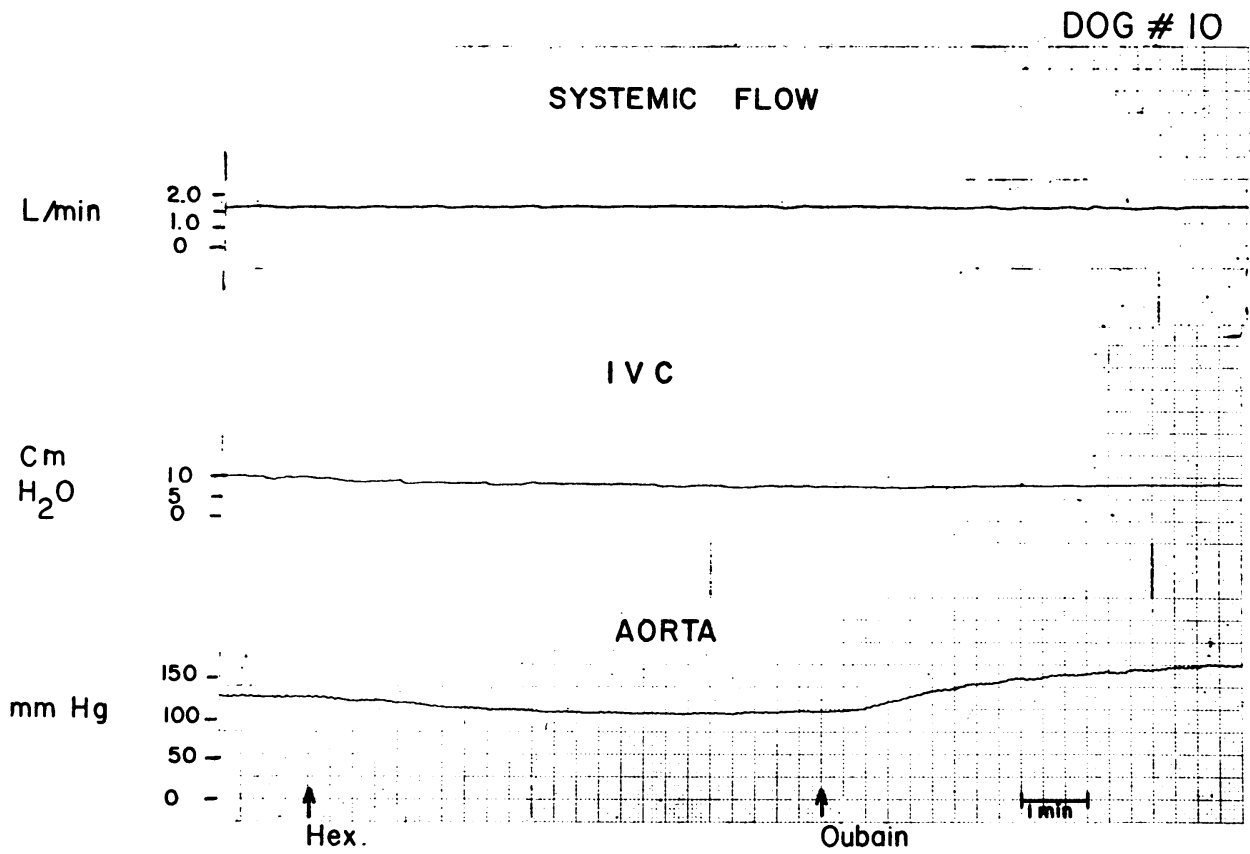

Fig. 4. Continuous recording of Systemic Flow, inferior vena Caval (IVC) ANd aOrtic PRESSURES. Hexamethonium infusion was begun at the vertical arrow on the left and resulted in a decline in both vena caval and aortic pressures. Ouabain, 0.83 cat $\mathrm{U}$ per $\mathrm{kg}$ was injected at the time of the arrow on the right.

\section{DISCUSSION}

Earlier investigators demonstrated that digitalis glycosides cause contraction of excised arterial (15) and venous (16) rings. More recently, Leonard also observed a contractile response of both arterial (17) and venous strips (18) to digitalis glycosides. In the intact dog, arterial pressure elevations have been shown to occur following digitalis administration $(1,2,7,19-21)$. In many studies, however, toxic doses of digitalis were given, and the absence of simultaneous cardiac output measurements prohibited conclusions concerning the direct effect of these drugs on peripheral vascular resistance. Recently, however, Cotten and Stopp (9) observed a decline in cardiac output and slight elevation of arterial pressure following acute digitalization of the open-chest dog.

The experiments described herein demonstrate that with the heart effectively removed from the circulation, the administration of digitalis glycosides in therapeutic doses produces a significant elevation of arterial pressure. This pressor response was: $a$ ) not prevented by ganglionic block- ade or adrenalectomy ; $b$ ) prevented in local portions of the vascular bed by their humoral isolation from the remainder of the animal's body; and c) induced locally by selective injection of the drug into the local vascular bed. The occurrence of a pressor response to digitalis injection into the humorally and hemodynamically isolated lower segment excluded the possibility that this response was mediated either through the adrenal medulla or through a reflex alone. Furthermore, since in Preparation 2 intravenous injection of digitalis into the upper segment resulted in a decrease in the vascular resistance of the perfused lower segment, a purely reflex origin of the pressor response seems even less likely. These experiments thus support the contention that the increase in vascular resistance results primarily from a direct action of the digitalis preparations on arteriolar smooth muscle.

In view of the suggestion that splanchnic vasoconstriction is largely responsible for arterial pressure elevations following digitalization (20), it is of interest that no apparent modification of the response was produced by splanchnic artery ligation. Vascular constriction in the hind limb ac- 
tually exceeded that which occurred in the remainder of the circulation, since in four of five dogs studied, femoral artery flow declined at a constant systemic perfusion rate.

Melville (22) described a reflex depression of digitalis-induced pressor responses in the dog, and postulated that digitalis may excite an intracardiac chemoreceptor reflex of the Jarisch-Bezold type. It is therefore possible that exclusion of the heart from the circulation might enhance the pressor response to digitalis. However, in this connection, it is pertinent that in the course of other perfusion studies, identical with those described herein, but without aortic occlusion, a 26 and a 53 per cent augmentation of peripheral vascular resistance occurred following digitalization with 0.5 cat unit per $\mathrm{kg}$ ouabain. In addition, the pressor response was not abolished in two of the adrenalectomized dogs in the present series in which the aorta was not occluded. Thus, a significant pressor response was observed even when the glycoside was permitted to reach the myocardium.

Preliminary observations have been carried out in patients undergoing total cardiopulmonary bypass at a constant perfusion rate. An increase in peripheral vascular resistance accompanied the inotropic effect resulting from the administration of acetylstrophanthidin (10). These data are consonant with the observations of Williams, Zohman and Ratner, who demonstrated an elevation of arterial pressure and systemic vascular resistance in human subjects undergoing rapid digitalization (23).

Possible clinical significance of the digitalis-induced elevations in vascular resistance has been suggested by Bayliss and co-workers, who reported the development of acute pulmonary edema following rapid digitalization (24). Perhaps, in these instances, the increase in peripheral resistance abruptly augments the left ventricular work before the positive inotropic action becomes manifest. On the other hand, it would seem that under appropriate conditions the vasoconstrictor effects of digitalis may be beneficial.

\section{SUMMARY}

The effects of acetylstrophanthidin, ouabain, and lanatoside $C$ on peripheral vascular resistance were studied in 46 dogs in which cardiac action was excluded by the use of cardiopulmonary bypass. At a constant perfusion rate a significant elevation of arterial pressure occurred in each instance and reflected an augmentation of peripheral vascular resistance. This elevation of arterial pressure was not abolished by ganglionic blockade or adrenalectomy and was not modified by splanchnic arterial ligation. The injection of acetylstrophanthidin into the constantly perfused lower aorta of four dogs resulted in a pressor response limited to this portion of the vascular bed, while injection into the upper segment of three dogs produced a reflex fall in pressure in the lower segment. These experiments support the view that a direct action of digitalis on arteriolar smooth muscle is responsible for the digitalisinduced increase in peripheral vascular resistance.

\section{REFERENCES}

1. Katz, L. N., Rodbard, S., Friend, M., and Rottersman, W. The effect of digitalis on the anesthetized dog. I. Action on the splanchnic bed. J. Pharmacol. exp. Ther. 1938, 62, 1.

2. Dock, W., and Tainter, M. L. The circulatory changes after full therapeutic doses of digitalis, with a critical discussion of views on cardiac output. J. clin. Invest. 1930, 8, 467.

3. Tainter, M. L., and Dock, W. Further observations on the circulatory actions of digitalis and strophanthus with special reference to the liver, and comparisons with histamine and epinephrine. J. clin. Invest. 1930, 8, 485.

4. McMichael, J. Pharmacology of the failing human heart. Brit. med. J. 1948, 2, 927.

5. Wiggers, C. J., and Stimson, B. Studies on the cardiodynamic actions of drugs. III. The mechanism of cardiac stimulation by digitalis and g-strophanthidin. J. Pharmacol. exp. Ther. 1927, 30, 251.

6. Cattell, M., and Gold, H. The influence of digitalis glucosides on the force of contraction of mammalian cardiac muscle. J. Pharmacol. exp. Ther. 1938, 62, 116.

7. Walton, R. P., Leary, J. S., and Jones, H. P. Comparative increase in ventricular contractile force produced by several cardiac glycosides. J. Pharmacol. exp. Ther. 1950, 98, 346.

8. Cotten, M. D., and Bay, E. Direct measurement of changes in cardiac contractile force. Relationship of such measurements to stroke work, isometric pressure gradient and other parameters of cardiac function. Amer. J. Physiol. 1956, 187, 122. 
9. Cotten, M. D., and Stopp, P. E. The action of digitalis on the nonfailing heart of the dog. Amer. J. Physiol. 1958, 192, 114.

10. Bloodwell, R. D., Goldberg, L. I., Braunwald, E., Gilbert, J. W., Ross, J., Jr., and Morrow, A. G. Myocardial contractility in man: The acute effects of digitalis, sympathomimetic amines, and anoxic cardiac arrest. Surg. Forum 1959, 10, 532.

11. Sarnoff, S. J., and Berglund, E. Ventricular function. I. Starling's law of the heart studied by means of simultaneous right and left ventricular function curves in the dog. Circulation 1954, 9, 706.

12. Waldhausen, J. A., Lombardo, C. R., McFarland, J. A., Cornell, W. P., and Morrow, A. G. Studies of hepatic blood flow and oxygen consumption during total cardiopulmonary bypass. Surgery 1959, 46, 1118.

13. Shipley, R. E., and Wilson, C. An improved recording rotameter. Proc. Soc. exp. Biol. (N. Y.) 1951, 78, 724.

14. Winbury, M. M. Comparison of the vascular actions of 1,1-dimethyl-4-phenylpiperazinium and tetramethyl ammonium. J. Pharmacol. exp. Ther. 1958, 124, 25.

15. Cow, D. Some reactions of surviving arteries. J. Physiol. 1911, 42, 125.

16. Franklin, K. J. The pharmacology of the isolated vein ring. J. Pharmacol. exp. Ther. 1925, 26, 215.
17. Leonard, E. Alteration of contractile response of artery strips by a potassium-free solution, cardiac glycosides, and changes in stimulation frequency. Amer. J. Physiol. 1957, 189, 185.

18. Leonard, E. Personal communication.

19. Cushny, A. R. On the action of substances of the digitalis series on the circulation in mammals. J. exp. Med. 1897, 2, 233.

20. Gottlieb, R., and Magnus, R. Ueber die Gefässwirkung der Körper der Digitalisgruppe. NaunynSchmiedeberg's Arch. exp. Path. Pharmak. 1902, 47, 135.

21. Cohn, A. E., and Levy, R. L. The effect of therapeutic doses of digitalis on the contraction of the heart muscle. Proc. Soc. exp. Biol. (N. Y.) 1920, 17,160 .

22. Melville, K. I. $O$ the mechanism of the cardiovascular actions of digitalis: Observations on the influence of flaxedil, atropine or vagotomy. $\mathrm{J}$. Pharmacol. exp. Ther. 1952, 106, 208.

23. Williams, M. H., Jr., Zohman, L. R., and Ratner, A. C. Hemodynamic effects of cardiac glycosides on normal human subjects during rest and exercise. J. appl. Physiol. 1958, 13, 417.

24. Bayliss, R. I. S., Etheridge, M. J., Hyman, A. L., Kelly, H. G., McMichael, J., and Reid, E. A. S. The effect of digoxin on the right ventricular pressure in hypertensive and ischaemic heart failure. Brit. Heart J. 1950, 12, 317. 